\title{
Assess the Effectiveness of Planned Teaching on Knowledge Regarding Cervical Cancer with Human Papiloma Virus (HPV) Vaccination Among Women in Urban Area
}

\author{
Pradnya Sakle1, Shaigy Mol James², Shubham Meshram³, \\ Sheetal Karluke ${ }^{4}$, Shubham Rangari ${ }^{5}$ and SnehaYelne ${ }^{6}$ \\ 1,2,3,4,5,6UG Students, Smt. Radhikabai Meghe Memorial College of \\ Nursing, Datta Meghe Institute of Medical Sciences, (Deemed to \\ be University), Sawangi Meghe, Wardha, India
}

\section{ABSTRACT}

Cervical cancer is second only to breast cancer on the most common type of cancer found in women worldwide. It affects an estimated 500,000 women each year. In United States and other developing countries, the rates of cervical cancer are much lower, in fact, according to National Cervical Cancer Coalition, more than $80 \%$ of all cases of cervical cancer occur in developing countries.Objectives:1.To assess the knowledge regarding cervical cancer with HPV vaccination.2.To assess effectiveness of planned teaching on knowledge regarding cervical cancerwith HPV vaccination.3.To associate the findings with selected demographic variables. Materials and Methods: 80 samples were selected from women in urban areas by Purposive sampling technique. Pre Experimental research design one group Pre test and post test without control group design was used. Findings revealed that in pre test32 women (40\%) had poor level of knowledge and 48(60\%) of women had average level of knowledge score, no women (0\%) had good level of knowledge and $0(0 \%)$ of them had excellent level of knowledge score. The minimum score was 0 and the maximum score was 10 , the mean score was $5.85 \pm 2.571$ with a mean percentage score of $29.25 \pm 12.855$.In post test only 1 woman $(1.25 \%)$ had poor level of knowledge score, 12 women (15\%) had average level of knowledge score, 33 women had good level of knowledge score and 34 women had excellent level of knowledge score. The minimum score was 05 and the maximum score was 19, the mean score was $13.95 \pm 3.438$ with a mean percentage score of $69.75 \pm 17.19$ The main aim of the study was assess the effectiveness of planned teaching on knowledge regarding cervical cancer with Human papiloma Virus (HPV) vaccination among women in urban area of wardha city. Information is given to the women through a planned teaching which includes various aspects like general knowledge regarding cervical cancer, epidemiology, risk factors, causes, stages, HPV vaccination, complications, prevention and treatment of cervical cancer with HPV vaccination.

KEY WORDS: CERVICAL CANCER, HUMANPAPILOMA VIRUS (HPV).

\section{ARTICLE INFORMATION}

Received 12th Oct 2020 Accepted after revision 29th Dec 2020 Print ISSN: 0974-6455 Online ISSN: 2321-4007 CODEN: BBRCBA

Thomson Reuters ISI Web of Science Clarivate Analytics USA and Crossref Indexed Journal

\section{Clarivate
Analytics}

NAAS Journal Score 2020 (4.31)

A Society of Science and Nature Publication,

Bhopal India 2020. All rights reserved.

Online Contents Available at: http//www.bbrc.in/

Doi: $h$ ttp://dx.doi.org/10.21786/bbrc/13.15/46

\section{INTRODUCTION}

Cervical cancer is a major and devastating cause of mortality worldwide with an estimated global incidence of 5 lakhs new cases and 2.7 lakhs deaths annually among women. It is the second most common cancer in women between 15 and 45 years of age and the third most common cause of cancer related mortality in women. According to WHO/ICO information centre on

\section{8}


HPV and cervical cancer (2009) in India, women at risk of cervical cancer is 366.58 millions, 1.3 lakhs of annual cases and 74 thousand annual deaths. Statistical data reveals that the prevalence rate was highest in Mum bai(3121),Chennai(2550),Poona (1138),Trivandrum and Karunagappally 284 and 93 respectively. Unless there is a dramatic improvement in prevention of cervical cancer and the incidence of the disease falls by 2050, one million new cases of the disease will be diagnosed each year. Worldwide, cervical cancer is both the fourth- most common causes of cancer and the fourth- most common causes of death from cancer in women.In 2012, an estimated 528,000 cases of cervical cancer occurred, with 266,000 deaths. About 70\% of cervical cancer occurs in developing countries. Also cervical cancer is a cancer arising from cervix.

It is due to the abnormal growth of cell that have the ability to invade or spread to other parts of the body. Early on, typically no symptoms are seen. Later symptoms may include abnormal vaginal bleeding, pelvic pain or pain during sexual intercourse. Long term infection with certain type of the HPV is now known to be the causes of almost all cervical cancer. Almost all abnormal Pap test result is caused by HPV. In 2006, "Professor Ian Frazer" and his team at the "University of Queensland" discovered a vaccine to prevent HPV, and protecting women against most types of cervical cancer. HPV is commonly spread by sexual contact as many people may not be aware of signs and/ or symptoms. HPV does not always leads to cervical cancer. However if the virus persists and is left undetected, the viral cell can become cancerous.

\section{MATERIAL AND METHODS}

Source of Data: Data collected from women in the urban area. Inclusion Criteria: Inclusion criteria:-1. Available at the time of data collection.2.Able to understand the language Marathi or Hindi.3.Age group of women 18 years to 55 years.4. Willing to participate in study. Exclusion criteria:-1.Those who are suffering from chronic illness like any type of cancer. 2.Those who are Health professionals.3.Those who have attended health educational programme regarding cervical Cancer. Research Approach: Quantitative approach Research Design: Evaluative research design Setting:Research conducted in urban area. Sampling Technique: Purposive sampling technique. Sample size: The total samples of the study consist of 80 womenTools of Research: Data collection tool is self-administered structured knowledge questionnaire which consists of following aspects. Section-I: Deals with demographic variables. Section-II: Deals with self-administered structured knowledge questionnaire on cervical cancer and HPV vaccine.Section-III:knowledge regarding cervical cancer and HPV vaccine.Independent variable: knowledge of cervical cancer with HPV vaccinationDependent variable: women.

The above table shows that in pre test32 women (40\%) had poor level of knowledge and $48(60 \%)$ of women had average level of knowledge score, no women (0\%) had good level of knowledge and $0(0 \%)$ of them had excellent level of knowledge score. The minimum score was 0 and the maximum score was 10 , the mean score was $5.85 \pm$ 2.571 with a mean percentage score of $29.25 \pm 12.855$. In post test only 1 woman (1.25\%) had poor level of knowledge score, 12 women (15\%) had average level of knowledge score, 33 women had good level of knowledge score and 34 women had excellent level of knowledge score. The minimum score was 05 and the maximum score was 19 , the mean score was $13.95 \pm 3.438$ with a mean percentage score of $69.75 \pm 17.19$.

Graph : Significance of difference between knowledge score in pre and post test of women regarding cervical cancer with HPV vaccination.

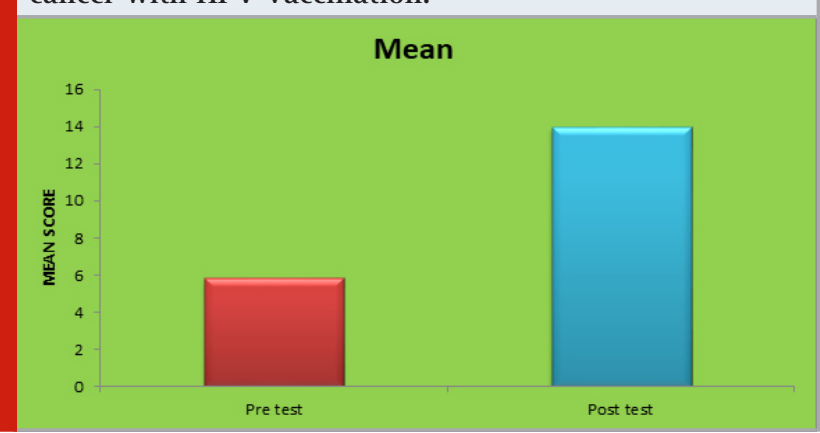

This table shows the comparison of pre test and post test knowledge scores of women regarding cervical cancer with HPV vaccination. Mean, standard deviation and mean percentage score values are compared and student's paired test is applied at 5\% level of significance. The tabulated value for $n=80-1$ i.e 79 degrees of freedom was 2.68 . The calculated value was 27.778 for overall knowledge score. The calculated 't' value are much higher than the tabulated value at 5\% level of significance which is statistically acceptable level of significance. Hence it is statistically interpreted that that planned teaching on knowledge regarding cervical cancer with HPV vaccinationwas effective. Thus the $\mathrm{H} 1$ is accepted.

\section{DISCUSSION}

Assess the effectiveness of planned teaching on knowledge regarding cervical cancer with Human papiloma Virus (HPV) vaccination among women in urban area was undertaken with the objectives to assess the knowledge regarding cervical cancer with HPV vaccination, to ascertain the relationship with selected sociodemographic variable and to find out the deficit areas. The study accessible population was women of selected urban area of wardha city. 80 women were selected by purposive sampling technique. Data was collected from women by questionnaire. Data was analyzed by descriptive and inferential statistics and presented through tables and figures. As per objectives it was found that the existing knowledge before teaching was satisfactory in pre test mean percent was $29.25 \%$ and knowledge of women in post test mean percent was $69.75 \%$. Education variable was found to be associated with knowledge of women 
none of the others variable were found significantly related with the knowledge of women.This study is supported to my study and education variable found to be significant with knowledge of women and others variable are not being found significantly.

\begin{tabular}{|c|c|c|c|c|}
\hline \multirow{2}{*}{$\begin{array}{l}\text { Level of knowledge } \\
\text { score }\end{array}$} & \multirow[t]{2}{*}{ Score range } & \multirow{2}{*}{$\begin{array}{l}\text { Percentage } \\
\text { score }\end{array}$} & \multicolumn{2}{|c|}{ Knowledge Score } \\
\hline & & & Pre Test & Post Test \\
\hline Poor & $0-5$ & $1-25 \%$ & $32(40 \%)$ & $1(1.25 \%)$ \\
\hline Average & $6-10$ & $26-50 \%$ & $48(60 \%)$ & $12(15 \%)$ \\
\hline Good & $11-15$ & $51-75 \%$ & $0(0 \%)$ & $33(41.25 \%)$ \\
\hline Excellent & $16-20$ & $>76 \%$ & $0(0 \%)$ & $34(42.5 \%)$ \\
\hline \multicolumn{3}{|l|}{ Minimum score } & 0 & 5 \\
\hline \multicolumn{3}{|l|}{ Maximum score } & 10 & 19 \\
\hline \multicolumn{3}{|l|}{ Mean score } & $5.85 \pm 2.571$ & $13.95 \pm 3.438$ \\
\hline \multicolumn{3}{|l|}{ Mean \% } & $29.25 \pm 12.855$ & $69.75 \pm 17.19$ \\
\hline \multicolumn{3}{|l|}{ t-value } & 17.743 & \\
\hline \multirow{2}{*}{\multicolumn{3}{|c|}{ p-value }} & 0.00 & \\
\hline & & & S,p<0.05 & \\
\hline
\end{tabular}

An evaluative approach with one group Pre testPost test design was used for the study. 80 samples were selected using simple random sampling method. The present study was conducted in Arvi-naka, wardha city. The collected data were analyzed using descriptive and inferential statistics. A significant difference between Pre test and Post test knowledge was found $(t=17.743, \mathrm{~S}, \mathrm{p}<0.05)$. In pre test mean percent was $29.25 \%$ and in post test mean percent was $69.75 \%$. There was no significant association between the level of knowledge and demographic variables such as age, educational status, family type, marital status occupational status. This study supported to my study and in my study planned teaching was effective in improving the knowledge of women regarding prevention of cervical cancer with HPV vaccination.

\section{CONCLUSION}

The main aim of the study was assess the effectiveness of planned teaching on knowledge regarding cervical cancer with Human papiloma Virus (HPV) vaccination among women in urban area of wardha city. Information is given to the women through a planned teaching which includes various aspects like general knowledge regarding cervical cancer, epidemiology, risk factors, causes, stages, HPV vaccination, complications, prevention and treatment of cervical cancer with HPV vaccination.

\section{REFERENCES}

Curtin, J.P., Blessing, J.A., Webster, K.D., Rose, P.G., Mayer, A.R., Fowler Jr, W.C., Malfetano, J.H. and Alvarez, R.D., 2001. Paclitaxel, an active agent in nonsquamous carcinomas of the uterine cervix: a Gynecologic Oncology Group Study. Journal of clinical oncology, 19(5), pp.1275-1278.

Denny, L., 2005. The prevention of cervical cancer in developing countries. BJOG: An International Journal of Obstetrics \& Gynaecology, 112(9), pp.1204-1212.

Jones, W.B., Mercer, G.O., Lewis Jr, J.L., Rubin, S.C. and Hoskins, W.J., 1993. Early invasive carcinoma of the cervix. Gynecologic oncology, 51(1), pp.26-32.

Monk, B.J. and Montz, F.J., 1992. Invasive cervical cancer complicating intrauterine pregnancy: treatment with radical hysterectomy. Obstetrics and gynecology, 80(2), pp.199-203.

Plummer, M., Herrero, R., Franceschi, S., Meijer, C.J., Snijders, P., Bosch, F.X., de Sanjosé, S. and Muñoz, N., 2003. Smoking and cervical cancer: pooled analysis of the IARC multi-centric case-control study. Cancer Causes \& Control, 14(9), pp.805-814.

Therasse, P., Arbuck, S.G., Eisenhauer, E.A., Wanders, J., Kaplan, R.S., Rubinstein, L., Verweij, J., Van Glabbeke, M., van Oosterom, A.T., Christian, M.C. and Gwyther, S.G., 2000. New guidelines to evaluate the response to treatment in solid tumors. Journal of the National Cancer Institute, 92(3), pp.205-216. 